CASE NOTES

\title{
HERNIA OF THE CHOROID TREATED BY SCLERAL GRAFTING FOLLOWED BY DIRECT SUTURING OF THE SCLERA*
}

\author{
BY \\ P. SIVASUBRAMANIAM AND T. HOOLE \\ Eye Clinic, Civil Hospital, Jaffna, Ceylon
}

\section{Case Report}

A young man aged 18 had had a bluish-black lump on the "white" of the left eye for 8 years. He did not recall any injury to this eye and had had no inflammation.

Examination.-A bluish-black sessile swelling was seen on the superonasal side of the left eyeball about $4 \mathrm{~mm}$. from the limbus (Figure). The lump measured $6 \times 4 \mathrm{~mm}$., the long axis being more or less tangential to the limbus. The swelling was cystic, tense, slightly reducible, nonpulsatile, and non-transluminant. It was not movable over the globe, the conjunctiva over it was stretched and tenuous. Biomicroscopy revealed a deposit of fine iris pigment on the lens capsule at the lower part. There was no sign of active uveitis. Visual acuity was $6 / 6$ in each eye. Digital tonometry indicated that the tension was equal in both eyes. The fundi were normal. The region of the ectasia was not accessible ophthalmoscopically. Wassermann reaction negative.

Operations.-Scleral grafting and direct suturing of the scleral hiatus were performed at different times. The reports of Lister (1951) on scleral grafting prompted us to try this operation.

(1) January 21, 1953.-Under retro-ocular novocaine and local anaesthesia the conjunctiva over the lump was neatly dissected and an upper flap was raised. The margins of the lump were well defined with a cataract knife and a pair of fine forceps. The edges of the scleral hiatus were freshened with a knife. A scleral graft $6 \mathrm{~mm}$. round was cut from a donor eye (this was excised within 2 hours of death from an eye from which a corneal graft had been taken the same day). It was placed over the summit of the lump to test accuracy of fit. Though the hiatus was oval adjustments were made while suturing. Silk sutures were passed through the margins of the scleral hiatus and the graft; a para-

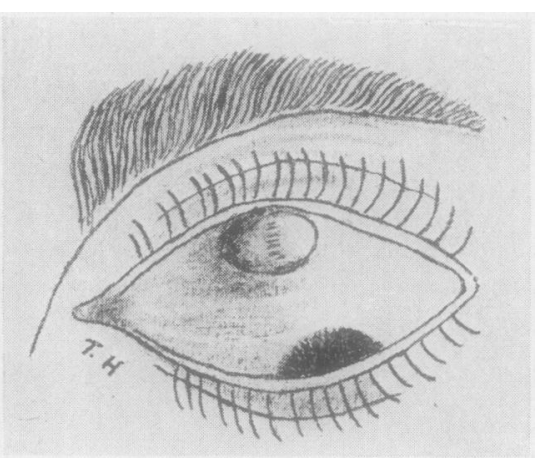

FIGURE.-Position of herniation and its relationship to the limbus. centesis of the anterior chamber at this stage effectively collapsed the lump, and allowed the sutures to be drawn tight and knotted. The flap of conjunctiva was drawn over the graft and sutured. Gutt. atropine 1 per cent. was instilled and a crêpe elastic bandage was applied over a heavy dressing.

Post-operative Course.-The eye was inspected on the fourth post-operative day. The graft was in place, there was marked swelling of the conjunctiva, and the lump was reappearing. Pressure bandaging was continued. On February 4, 1953, a paracentesis was repeated and the pressure bandaging continued. The ectasia had fully reappeared within a week. The scleral graft had united with the superonasal margin of the scleral hiatus

*Received for publication July 27, 1953. 
but was disunited elsewhere. The graft, however, had taken and though lifted up on the summit of the ectasia was inseparably united to the underlying choroid. The area immediately surrounding the site of operation was a little injected, there being no uveal inflammation. Atropine was stopped and the patient allowed to go home on April 30, 1953.

(2) May 20, 1953.- Under local anaesthesia supplemented by retro-ocular novocaine the conjunctiva was reopened and the edges of the scleral opening were found to be clearly defined. Four catgut sutures $6 / 0$ on atraumatic needles were passed through the scleral hiatus. A paracentesis of the anterior chamber was done at this stage to collapse the lump. The sutures were drawn taut invaginating the bulging choroid surmounted by the scleral graft. The lips of the scleral gap were well apposed and no portion of the choroid was seen to bulge into the wound. The conjunctiva was drawn over the scleral wound. Pressure bandaging was effected by a large pad and crêpe elastic bandage.

Four days after the operation the wound was seen to be healing with no tendency for the choroid to bulge. At this time a blackish swelling was seen within the eye corresponding in site exactly to the herniation on the surface prior to operation. This was obviously the recently returned choroid and the scleral graft riding on it. When the eye was examined ophthalmoscopically in another 3 days' time this fundus swelling appeared rather like a choroidal detachment. Vision was $6 / 12$. With further rest and treatment the wound healed and on June 6,1953 , the visual acuity was $6 / 6$, and the eye was practically white.

\section{Comment}

This is a rare form of ocular deformity and was in all probability traumatically induced though the boy could not remember any injury. This type of ectasia is sometimes seen in Ceylon and may be caused by bursting aerated water bottles, broken glass bangles, or the misadventures of quacks practising under the cloak of Ayurveda who attempt to remove scleral nodules with razor blades!

The treatment adopted has some bearing on the topic of scleral grafting, though in the case reported the graft failed to check the ectasia. The case disproves the popular belief that the normal intra-ocular pressure has no effect on the choroid in that it does not cause the latter to bulge. The case of scleromalacia perforans is cited as an example of the choroid's ability to withstand the normal intra-ocular pressure, for in this condition in spite of large defects in the sclera the choroid does not bulge.

Those engaged in doing full-thickness scleral resections know how difficult it is to keep the choroid from bulging. Regarding scleral grafting, Rycroft (1951) states that undue reactions after these operations were due to autoplasty inferring that if grafts were taken from the same eye or from the fellow eye of the same patient such untoward reactions would not be met with. Lister (1951), however, used cadaver material and so did we, with minimal reactions.

Buccal mucosa and conjunctiva have also been used to cover scleral defects in cases of scleromalacia perforans (François, 1951), and Paufique (1950) is reported to have performed scleral grafting in a case of scleromalacia perforans (François, 1951). As in our case the graft took easily, we would suggest that scleral grafts be given further trial in deficiencies in the sclera from whatever cause. It is interesting to speculate on the feasibility of using scleral caps in scleral grafting much in the manner of plastic corneal caps for corneal grafting. These caps might check the choroidal bulge while the graft consolidated itself.

\section{REFERENCES}

FrançoIs, J. (1951). Trans. ophthal. Soc. U.K., 71, 61.

LISTER, A. (1951). Ibid., 71, 97.

PAUfIQUe, L. (1950). Cited by François (1951). Ibid.. 71, 72.

RYCROFT, B. W. (1951). Ibid., 71, 108. 